\title{
Dynamics of fish populations with different compensatory processes when subjected to random survival of eggs and larvae ${ }^{1}$
}

\author{
A.L. Jensen \\ School of Natural Resources, University of Michigan, Ann Arbor, MI, USA
}

(Received 14 August 1991; accepted 1 September 1992)

\begin{abstract}
Jensen, A.L., 1993. Dynamics of fish populations with different compensatory processes when subjected to random survival of eggs and larvae. Ecol. Modelling, 68: 249-256.

It is widely believed that abundance of fish populations is determined during the larval stage, for larval abundance is high, there is high variability in larval survival, and small changes in larval abundance could have large effects on population abundance. In this study, hypothesized population regulation processes were quantified in a mathematical model that was applied to study the importance of compensatory processes during the larval stage by replacing them with random survival. The hypothesized population regulation processes were food-limited growth, size-dependent mortality, and age at maturity dependent on size. Variation in population abundance resulting from variation in egg and larval survival depends on the population regulation process. In populations where mortality depends on size of individuals, variation in survival of young has little effect on abundance of adults. If age at maturity is flexible, variation in survival of young causes large fluctuations in abundance and the fluctuations follow a pattern of occasional large year classes that are slowly attrited over their lifespans. If age at maturity is not flexible, and if mortality is not size dependent, variation in survival of young causes population abundance to fluctuate widely without a clear pattern. Compensation during the larval life stage was not necessary for regulation of fish population size.
\end{abstract}

\section{INTRODUCTION}

It is widely believed that abundance of fish populations is determined during the larval stage (e.g., Hjort, 1914; Beverton and Holt, 1957; Lasker, 1975; Ricker, 1975). Larval abundance is high for most fish species and a

Correspondence to: A.L. Jensen, School of Natural Resources, University of Michigan, Ann Arbor, MI 48109-1115, USA.

${ }^{1}$ Supported in part by the Detroit Edison Company, Detroit, Michigan. 
large effect on population abundance can result from small changes in larval survival. Many studies have examined the larval life stage in an attempt to elucidate the relation of larval survival to population abundance, but these studies have achieved only limited success (e.g., Rothschild, 1986). The relation of larval growth and survival to population size is difficult to study in the laboratory because population densities there are many times higher than in the field, and laboratory environments do not have the complexity of natural environments. Study of larvae in the field also is difficult because a large number of interrelated factors operate, spatial and temporal variation are high, a single observation per year is obtainable for recruitment, data for early life stages are highly variable and difficult to obtain, and small changes in larval survival rates, changes that are impossible to detect, are biologically significant; even carefully done field studies result in ambiguous conclusions (e.g., Serns, 1982, 1984; Inskip and Magnuson, 1983; Koslow et al., 1985; Tanaka, 1985).

Mathematical models can be applied to study the effects of egg and larvae survival on population abundance, and the importance of compensatory processes that occur during the larval stage can be evaluated by replacing these processes with random survival. In this study the effects of random egg and larval survival on population abundance were studied assuming food-limited growth, size-dependent mortality, and age at maturity dependent on size. The model was applied using data for the walleye (Stizostedion vitreum) population in the western basin of Lake Erie.

\section{THE MODEL AND PARAMETER ESTIMATION}

Simple, well-established relations among food abundance, growth, and mortality were applied. The components of the model were the same as those applied by Jensen $(1989,1991)$, but a random numbers generator was used to simulate random survival of eggs and larvae. The model combines Larkin's (1956) predator-prey model, Ursin's $(1967,1979)$ bioenergetic growth model, Ivlev's (1961) feeding model, the exponential mortality model, and the relation between mortality and size developed by Peterson and Wroblewski (1984). Jensen $(1989,1991)$ discusses the model in detail.

In simulations where egg survival was random, egg survival was modeled as a uniformly distributed random variable between 0 and 1 . In simulations where survival of larvae was random, the mean larval survival of 0.0021 in the deterministic model suggested a uniformly distributed random variable between 0 and 0.0042 with a mean of 0.0021 . When both egg and larval survival were random the survival rate from egg to YOY was obtained as the product of the random survival rates of eggs and larvae. The parameter estimates were the same as in earlier studies (Jensen, 1989, 1991). 


\section{RESULTS AND DISCUSSION}

The dynamics of the simulated populations depended on the adaptive processes that determined population size. All of the adaptive processes examined were based on food-limited growth. An inverse relation between walleye population density and growth rate, indicative of food-limited growth, has been well documented (Colby et al., 1979). Large variation in walleye growth rates may occur between year classes and among individuals of the same year class, and one of the most important factors affecting walleye growth rates is the amount of forage available (Colby et al., 1979).

In the simulations, food-limited growth together with egg production dependent on size of adults resulted in a slow increase in population size to a carrying capacity (Fig. 1A). This is a slow adaptive process in which change in population abundance changes availability of food per individual, and food availability effects growth which effects size and fecundity. With food-limited growth and random variation in egg survival there is considerable variation in abundance (Fig. 1B), but variation in abundance is much less than variation in egg survival (Fig. 2). Random variation in egg survival reduces mean population size slightly, and considerably increases the time required to reach a steady state (Fig. 1B). With food-limited growth and both larval and egg survival random there is more variation in abundance
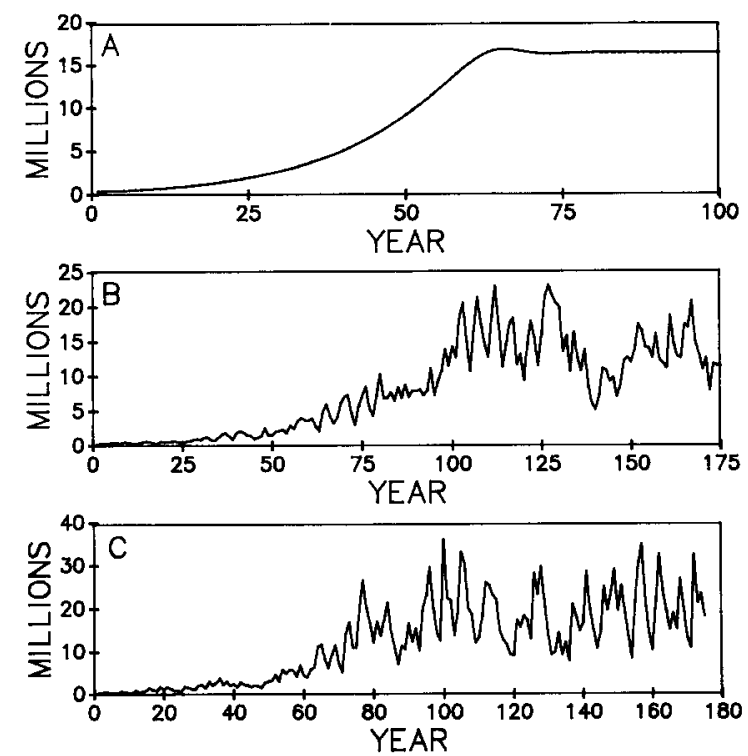

Fig. 1. Number of individuals with food-limited growth, egg production per gram constant, and (A) larval life stage modeled, (B) random egg survival and larval life stage modeled, and (C) egg and larval survival random. 


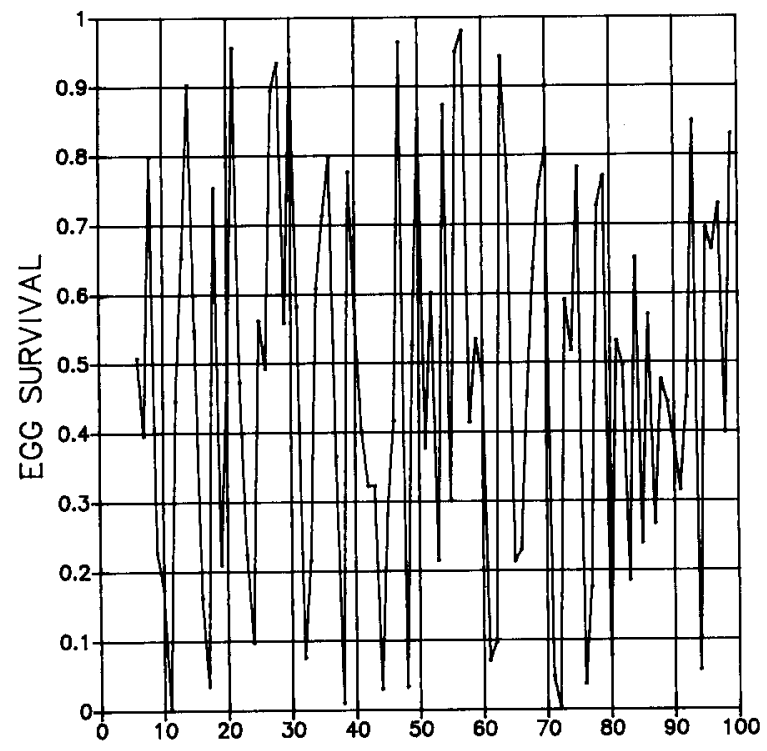

Fig. 2. Variation in survival of eggs.

than with only egg survival random. The increase in variation results mostly from large cohorts that sometimes occur, but these large cohorts do not persist; as the cohorts age mortality rapidly reduces their size (Fig. 1B and 1C). Mean population size with both random egg and larval survival is about the same as that with random egg survival.

Age at maturity varies considerably among walleye stocks, and a variable age at maturity has considerable potential for compensation (Jensen, 1991). Age at maturity is inversely related to growth rate, which in turn is affected by the amount of food available (Colby et al., 1979). A trend towards earlier maturity among more rapidly growing walleye has been reported in Oneida Lake, New York, and a similar trend was observed for heavily exploited stocks in Saginaw Bay (Lake Huron), the western basin of Lake Erie, and Dexter Lake, Ontario (Colby et al., 1979). In Lake Erie, the percent of walleye maturing at age 3 increased from 40 to 80 during a period when the stock size declined markedly (Shuter and Koonce, 1977).

In the simulations, when growth was food limited and age at maturity depended on size, there was a high potential for compensation, and the simulated population increased to a steady state rapidly (Fig. 3A). If age at maturity depends on size and survival is high, there are cycles in population abundance as age at maturity cycles from higher to lower values. If survival is low, age at maturity remains low and the cycles in population abundance disappear. If egg survival is random with age at maturity a function of size, there is a large increase in variation, but some of the pattern resulting from 

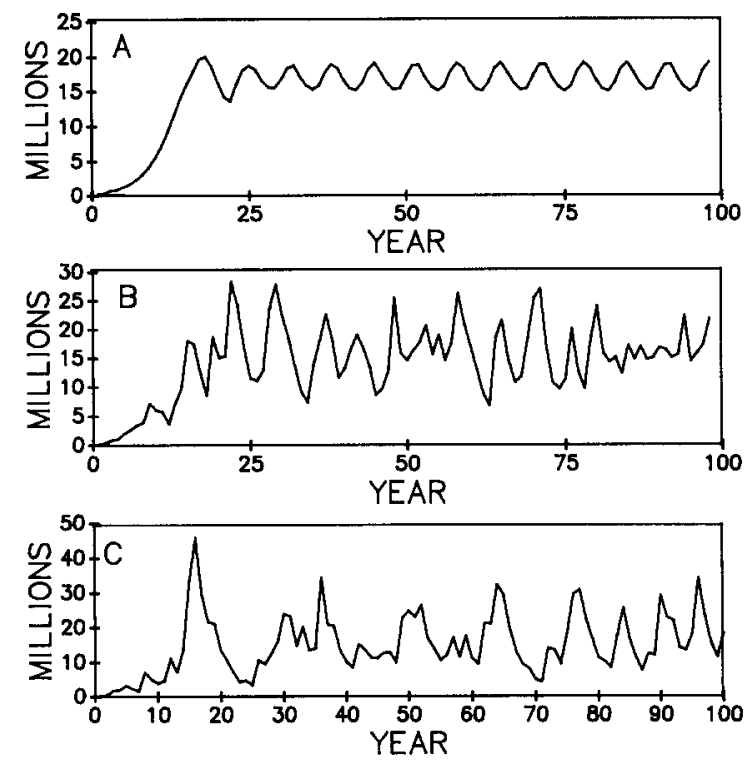

Fig. 3. Number of individuals with food-limited growth, age at maturity a function of size and (A) larval life stage modeled, (B) random egg survival and larval life stage modeled, and (C) egg and larval survival random.

variation in age at maturity remains (Fig. 3B). Mean population size is slightly lower with random egg survival. If both egg and larval survival are random, the pattern in population abundance is similar to that observed in yield data for many fish species (Fig. 3C).

A relation between mortality and size was reported for pelagic species by Peterson and Wroblewski (1984), and such a relation could occur in walleye populations, especially during early life stages where there is extensive predation. Walleye eggs are eaten by a large number of species, including carp, white perch, yellow perch, minnows, and suckers (Colby et al., 1979). Northern pike feed on walleye larvae, and other species such as saugers, bullheads, burbot, and yellow perch feed on walleye young-of-the-year (Colby et al., 1979). In the simulations, if mortality depends on size, the population quickly attains a carrying capacity (Fig. 4A). If mortality depends on size and egg survival is random, there is little fluctuation in population size (Fig. 4B), and abundance stays near the carrying capacity. If both egg and larval survival are random, there still is remarkably little variation in population size (Fig. 4C). These data are unlike data for natural populations, and they indicate that a close relation between mortality and size may not occur in natural environments.

The dynamics of a population with random variation of egg and larval survival depends on the processes that regulate population size. If mortality 

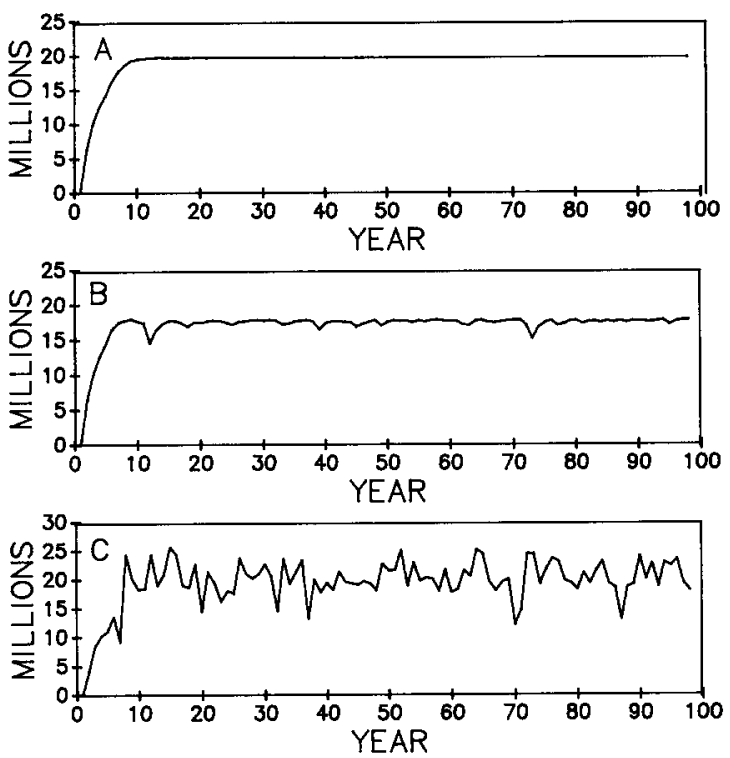

Fig. 4. Number of individuals with food-limited growth, mortality a function of size, and (A) larval life stage modeled, (B) random egg survival and larval life stage modeled, and (C) egg and larval survival random.

depends on size of individuals, large variation in survival of eggs and larvae has little effect on abundance of adults. A statistical relation between mortality and size might apply to species with pelagic eggs, larvae, and young. For species with a flexible age at maturity there are large fluctuations in abundance with random survival of eggs and larvae, and the fluctuations follow a pattern of occasional large year classes that are slowly attrited over their lifespans. If age at maturity is not flexible, and if mortality is not size dependent, population abundance fluctuates widely without a clear pattern. Compensation during the larval stage was not necessary for population regulation.

Ecological simulations, such as those done here, determine whether or not observed abundances can be described by hypothesized adaptive processes. The simulations indicate that random variation of eggs and larvae, together with the hypothesized compensatory processes, can produce patterns similar to those observed in nature. But, natural patterns also could result from other processes, such as non-random chaotic behavior (May, 1974) or interactions among species that result in chaotic, catastrophic, or other complex behavior (e.g., Starfield and Bleloch, 1986; Beltrami, 1987).

The capacity of a fish population to compensate for fishing mortality without compensation during the larval life stage was investigated by simulating exploitation with and without random survival of larvae for a 


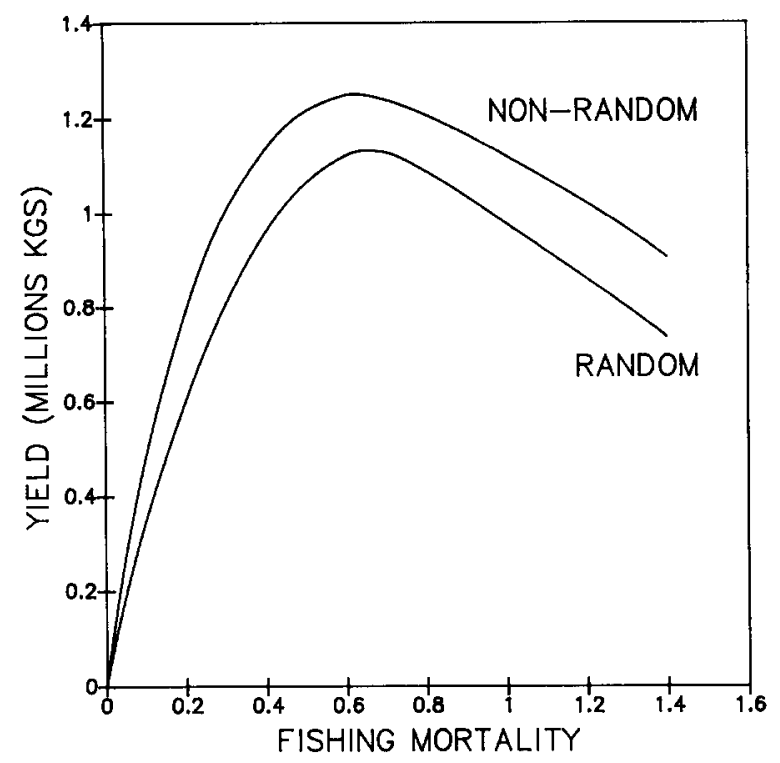

Fig. 5. Relation between yield and fishing mortality with food-limited growth and mortality a function of size with and without random survival of eggs and larvae.

population with size dependent mortality. If survival of both eggs and larvae are random, yield is slightly lower (Fig. 5), as was shown earlier by Beddington and May (1977), but clearly the larval life stage is not essential for compensation. In the simulations, it is the process of food-limited growth and its effects on egg production, age at maturity, and mortality that results in compensation.

\section{REFERENCES}

Beddington, J.R. and May, R.M., 1977. Harvesting natural populations in a randomly fluctuating environment. Science, 197: 463-465.

Beltrami, E., 1987. Mathematics for Dynamic Modeling. Academic Press, Boston.

Beverton, R.J.H. and Holt, S.J., 1957. On the dynamics of exploited fish populations. U.K. Min. Agric. Fish., Fish. Invest. (Ser. 2) 19.

Colby, P.J., McNicol, R.E. and Ryder, R.A., 1979. Synopsis of biological data on the walleye Stizostedion v. vitreum (Mitchell 1818). FAO Fisheries Synopsis 119.

Hjort, J., 1914. Fluctuations in the great fisheries of northern Europe in the light of biological research. Rapp. P.-V. Reun. Cons. Int. Explor. Mer, 20: 1-228.

Inskip, P.D. and Magnuson, J.J., 1983. Changes in fish populations over an 80-year period: Big Pine Lake, Wisconsin. Trans. Am. Fish. Soc., 112: 378-389.

Ivlev, V.S., 1961. Experimental Ecology of the Feeding of Fishes. Yale University Press, New Haven, Connecticut (translated from the Russian by Douglas Scott).

Jensen, A.L., 1989. Simulation of the potential for life history components to regulate walleye population size. Ecol. Modelling, 45: 27-41. 
Jensen, A.L., 1991. Simulation of fish population responses to exploitation. Ecol. Modelling, 55: 203-218.

Koslow, J.A., Frault, S., Dugas, J. and Page, F., 1985. Anatomy of an apparent year-class failure: the early life history of the 1983 Browns Band haddock Melanogrammus aeglefinus. Trans. Am. Fish. Soc., 114: 478-489.

Larkin, P.A., 1956. Interspecific competition and population control in freshwater fish. J. Fish. Res. Board Can., 13: 327-342.

Lasker, R., 1975. Field criteria for survival of anchovy larvae: the relation between inshore chlorophyll maximum layers and successful first feeding. U.S. Natl. Mar. Fish. Serv. Fish. Bull., 73: 453-462.

May, R.M., 1974. Biological populations with non-overlapping generations: stable points, stable cycles, and chaos. Science, 186: 645-647.

Peterson, I. and Wroblewski, J.S., 1984. Mortality rates of fishes in the pelagic ecosystem. Can. J. Fish. Aquat. Sci., 41: 1117-1120.

Ricker, W.E., 1975. Computation and interpretation of biological statistics of fish populations. Fisheries Research Board of Canada, Ottawa, Canada, Bull. No. 191.

Rothschild, B.J., 1986. Dynamics of Marine Fish Populations. Harvard University Press, Cambridge, MA.

Serns, S.L., 1982. Influence of various factors on density and growth of age-0 walleyes in Escanaba Lake, Wisconsin, 1958-1980. Trans. Am. Fish. Soc., 111: 299-306.

Serns, S.L., 1984. Walleye growth in relation to water temperature, food availability, and population density in Escanaba Lake, 1956-1982. Wisconsin Department of Natural Resources, Research Report 130, Madison.

Shuter, B.J. and Koonce, J.F., 1977. A dynamic model of the western Lake Erie walleye (Stizostedion vitreum vitreum) population. J. Fish. Res. Board Can., 34: 1972-1982.

Starfield, A.M. and Bleloch, A.L., 1986. Building Models for Conservation and Wildlife Management. Macmillan, New York.

Tanaka, M., 1985. Factors affecting the inshore migration of pelagic larval and demersal juvenile Red Sea bream Pagrus major to a nursery ground. Trans. Am. Fish. Soc., 114: 471-477.

Ursin, E., 1967. A mathematical model of some aspects of fish growth, respiration, and mortality. J. Fish. Res. Board Can., 24: 2355-2390.

Ursin, E., 1979. Principles of growth in fishes. Symp. Zool. Soc. London, 44: 63-87. 